\title{
Study on 3D Printing Technology Evolution and its Promotion Strategy from Cultural and Creative Industries: Based on the Patent Knowledge Map Analysis
}

\author{
Yuqing Liao ${ }^{1, \mathrm{a}}$ Jingliang Chen ${ }^{1, \mathrm{~b}}$ \\ ${ }^{1}$ Business School University of Shanghai for Science and Technology Shanghai, China
}

\begin{abstract}
In this paper, the application value for the Cultural and Creative Industries about 3D printing technology is explained. Based on the visualization analysis of the related technology patent literature, the technology evolution of 3D printing technology and its cutting-edge application field are discussed. With the patent knowledge map analysis, frontier technology has prospected, and it analyses the Cultural and Creative Industries revolution because of 3D technology development, and finally, some relevant policy is suggested.
\end{abstract}

\section{INTRODUCTION}

In the process of development of the cultural and creative industries, especially in the creative design stage, the dependence on science and technology is more obvious and more direct. With the diversification of 3D printing materials and the innovation of printing technology, 3D printing not only has great potential in the traditional manufacturing industry, but also extends to Cultural and Creative Industries such as film and television media, environmental art, advertising and decoration, clothing design, creative design Creative industry. 3D printing technology has become a new technology that integrates and intersects industrial production and art design, which is a key technology to promote the development of future model design, advertising design and architectural design technology. The continuous optimization and perfection of 3D printing technology provides an important guarantee for the leap-forward development of a new generation of art design and industrial design.

CiteSpace [1-3] as an information visualization software for measuring and analyzing scientific literature data, which uses a time-sharing dynamic visualization to show the macroscopic structure of scientific knowledge and the way it develops [4]. With the help of CiteSpace researchers, we can analyze not only the development trends and trends in related science but also technology fields through patent intelligence in related fields. This study combines the analysis results of CiteSpace to measure and visualize the patent literature data in the field of 3D printing technology [5], discover the development trend of 3D printing technology and the evolution trend of technology hotspots.

\section{Application Value ANd IndUStrial Significance of 3D Printing TeChNology in Cultural AND CREATIVE INDUSTRIES}

3D printing technology in recent years has become the industry-leading domain, even too concerned about the hot public opinion, public opinion on the application of technology price value and industrial development generally have higher expectations, 3D printing technologies emerge seen as a milestone for industrial development. With the continuous development of information technology, design software and digital tools continue to innovate and lay a solid foundation for the popularization of $3 \mathrm{D}$ printing applications. The application value and industrial significance of 3D printing technology in cultural and creative industries are mainly reflected in the following aspects:

Appear 3D printing makes the cultural and creative product design and development cycle of the entity into a progressive shortening. The rise of $3 \mathrm{D}$ printing technology makes personalized products manufactured in small quantities in a short time made possible by art and design of the model of the product from the creative design to greatly reduce the time entities, reduce time costs and improve high-efficiency rate, with when avoiding due prototyping and production outsourcing brings knowledge of risk property leakage, using 3D printing technology to enhance the design industry, the level of product development and industrial design capabilities.

3D printing provides the possibility of establishing complex physical models for industries related to the cultural and creative industries. For industrial design and art design, 3D printing is a convenient tool for constructing complex physical models. It can quickly produce products with complex shapes and provide

aliaoyuqing@usst.edu.cn bjingliangc@usst.edu.cn 
effective and convenient solutions for designers. 3D printing enhances the product development level and industrial design ability of the cultural and creative industries from the technical function, and the realization of value is more diverse.

\section{TECHNOLOGY FRONTIER AND EVOLUTION TREND ANALYSIS OF 3D PRINTING TECHNOLOGY}

In recent years, the number of patents related to $3 \mathrm{D}$ printing related technologies has shown a significant increasing trend. Through the analysis of the patented technology in the Derwent Patent Database (DII), the technical hotspots are mainly focused on 3D printing technology and data processing and model-building technology.

\section{A. 3D printing technology patent data measurement analysis}

3D printing data to complete resistance, in Derwent special interest database to ("3D Printing" or "3D Printing" or "Three-dimensional Printing" or "Three dimensional Printing Model" or "Three dimensional Printing " or "three dimensional printer" OR "threedimensional printer" or "3D printer" or "3-D printer") is a search for the subject of 3D printing technology, with a year span of 1963-2020. A total of 30562 related patents were retrieved, and the date of the search was March 4, 2020. The relevant data was selected in the form of "full record" as the data of this study. Statistics on the obtained patent data and the number of patent applications related to $3 \mathrm{D}$ printing technology in each year is shown in Figure 1. From this, we can see the trend of the development of 3D printing technology.

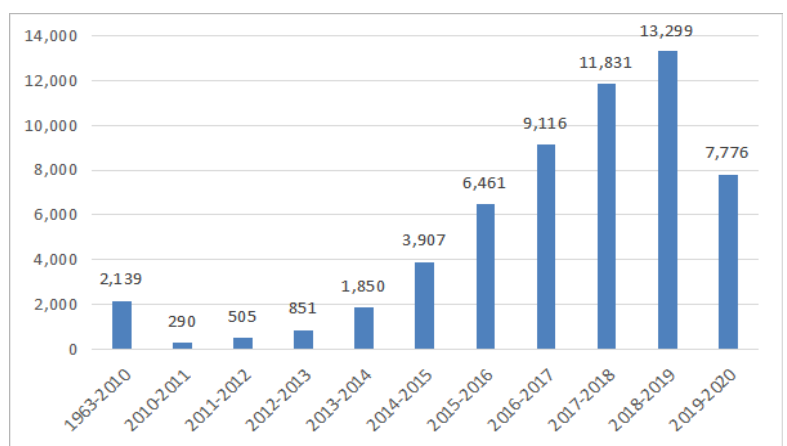

Figure 1. 3D printing technology patent quantity trend chart

Figure 1 is a bar chart showing the annual trend of the number of patents for 3D printing technology from 1963 to 2020. It can be observed from the Fig.1. That from 1963 to 2010, the number of relevant technology patents was relatively small and stable in the previous period, growing slowly and modestly between 1910 and 2013. The number has grown rapidly since 2014 . Given that the recent 3D printing boom has just begun in 2010, many key technologies have not been perfected, its application areas have yet to be explored and the application form has not yet been finalized, starting from 2014 to trigger a boom in technology development. but holding steady on the whole situation. In the last two years, the number of patents has grown rapidly, and the number of patents has been increasing. In view of the recent $3 \mathrm{D}$ boom, and the trend of hotter, many key technologies have not yet been perfected, and its application fields have yet to be developed and the application forms have not yet been finalized. The patent application data can be used to evaluate the cycle of technology life. The technology life cycle is divided into four stages: introduction period, growth period, maturity period and recession period. [7] import of a small number of patents, growth will be rapid growth in the number of patents, patent number of mature growths was slowing trend, the number of patent maturity will be negative growth trend potential. It can be seen that $3 \mathrm{D}$ printing technology has passed through the introduction and growth period, is still in the maturity period, there is still room for further development.

\section{B. Research hotspots and cutting-edge analysis of $3 D$ printing technology}

The Derwent Manual Code (MC) was manually assigned to various patents by Derwent's indexers to represent the innovations of patented technology and its applications, which identify detailed technical areas and help to pinpoint a patent. The specific areas involved also facilitate the identification of technological frontiers. This paper converts the Derwent patent data format of the data used to obtain the WOS format that CiteSpace can handle. The conversion relationship of the main fields is shown in Table 1.

TABLE 1. THE RELATIONSHIP BETWEEN THE DERWENT DATA FORMAT OF THE MAIN FIELDS AND THE WOS DATA FORMAT

\begin{tabular}{lll}
\hline $\begin{array}{c}\text { Derwent } \\
\text { data } \\
\text { format type } \\
\text { field }\end{array}$ & represents content & WOS format field \\
\hline $\mathrm{AU}$ & inventor & $\mathrm{AU}$ \\
$\mathrm{MC}$ & Derwent manual code & $\mathrm{DE}$ \\
$\mathrm{CP}$ & Special interest & $\mathrm{CR}$ \\
& citations & \\
\hline
\end{tabular}

Import the converted data into the CiteSpace software, with the keyword(category) as the node, year selection is 2010-2019 with a time slice of 1 year. And set Top $N=50$, that is, each time slice within the frequency ranking of the top 50 data, while selecting the Pathfinder pathfinding algorithm, and pruning sliced network function to trim the redundant network connections, the final number of nodes to get a 168 , network density $\mathrm{E}=372$ (Density=0.0265) of the $3 \mathrm{D}$ printing technology patent de Winter hand code total cited network map, as shown in Fig.2. 


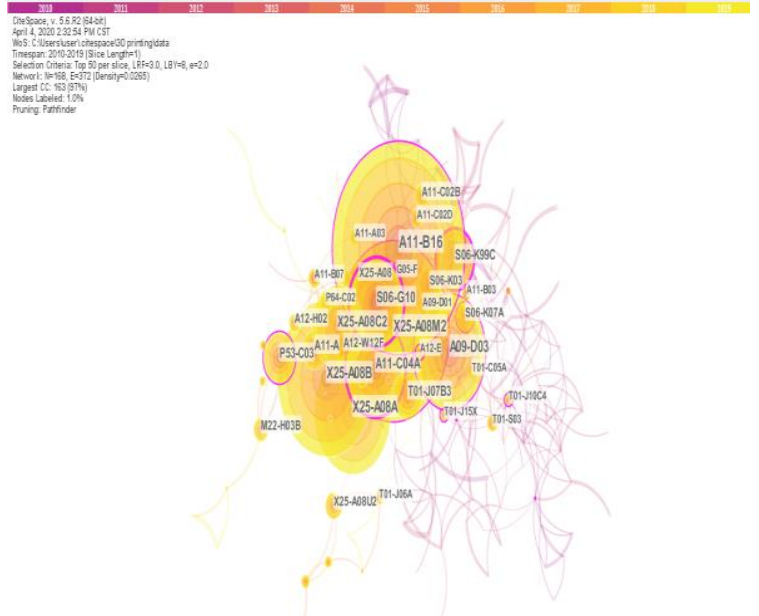

Figure 2. 3D printing technology patented Derwent manual code cocited network map

The map consists of nodes and texts representing Derwent's manual code. A total of 168 manual code nodes are involved. The overall network density is moderate. There is a certain technical communication between the patents through the marked manual code. The size of the node ring in Figure 2 is related to the frequency of the number of times the manual code is marked. The larger the ring, the more frequently the manual code is marked, and it is an area in which the manual code mark of the 3D printing technology is more. Explain that the relevant patents are more involved in this field. Click Citation Burst, Spectrum of the relevant node will be the center of a red circle with a red circle node for a certain circle of emergent Derwent manual codes, field indicates it represents a period of time is related patent number tag Sudden increase, can be understood as the research frontier of related technology patents in a certain period of time. Table 2 lists the top five Derwent manual codes for the frequency of occurrence, representing the main application areas and hotspots of 3D printing technology.
TABLE 2. 3D printing technology appears in the top five Derwent manual code

\begin{tabular}{|c|c|c|c|c|c|}
\hline index & $\begin{array}{c}\text { Mark } \\
\text { frequency }\end{array}$ & $\begin{array}{l}\text { Center } \\
\text { degree }\end{array}$ & years & $\begin{array}{c}\text { Derwent } \\
\text { manual } \\
\text { code }\end{array}$ & $\begin{array}{l}\text { Technical } \\
\text { field }\end{array}$ \\
\hline 1 & 5712 & 0.12 & 2010 & $\begin{array}{l}\text { A11- } \\
\text { B16 }\end{array}$ & $\begin{array}{l}\text { Stereographic } \\
\text { moulding }\end{array}$ \\
\hline 2 & 4741 & 0.18 & 2014 & $\begin{array}{l}\text { X25- } \\
\text { A08M2 }\end{array}$ & Plastics \\
\hline 3 & 4091 & 0.01 & 2014 & $\begin{array}{l}\text { X25- } \\
\text { A08B }\end{array}$ & $\begin{array}{l}\text { 3D printing / } \\
\text { additive } \\
\text { manufacturing } \\
\text { apparatus }\end{array}$ \\
\hline 4 & 3307 & 0.09 & 2014 & $\begin{array}{l}\text { X25- } \\
\text { A08A }\end{array}$ & $\begin{array}{l}3 \mathrm{D} \text { printing / } \\
\text { additive } \\
\text { manufacturing } \\
\text { methods }\end{array}$ \\
\hline 5 & 3139 & 0.11 & 2011 & $\begin{array}{l}\text { A09- } \\
\text { D03 }\end{array}$ & $\begin{array}{l}\text { Equipment } \\
\text { control, safety } \\
\text { devices others } \\
\text { [exc. for } \\
\text { moulding } \\
\text { processes, } \\
\text { involving } \\
\text { extruders] }\end{array}$ \\
\hline
\end{tabular}

According to the frequency of citation, the A11-B16 code is the most frequently marked manual code of $3 \mathrm{D}$ printing technology patents, indicating that it represents the most involved field of $3 \mathrm{D}$ printing technology, but also the most basic involved field, its code meaning is "Stereographic moulding". The field was searched for 5,712 times for 3D printing-related technology patents, with the nodes corresponding to the largest circles in Figure 2. This is followed by Plastics, whose manual code has been marked 4741 times by related patents. Meanwhile, the hot areas of 3D printing technology include additive manufacturing apparatus (X25-A08B), additive manufacturing methods (X25-A08A), equipment control, safety devices others (A09-D03). As can be seen from the frequency of being tagged, the technology hotspots of 3D printing-related patents are mainly focused on modeling and molding technology and added material technology.

TABLE 3. 3D printing technology center top five Derwent manual code

\begin{tabular}{|c|c|c|c|c|c|}
\hline index & $\begin{array}{l}\text { Center } \\
\text { degree }\end{array}$ & $\begin{array}{l}\text { Mark } \\
\text { frequ } \\
\text { ency }\end{array}$ & years & $\begin{array}{c}\text { Derwent } \\
\text { manual } \\
\text { code }\end{array}$ & $\begin{array}{l}\text { Technical } \\
\text { field }\end{array}$ \\
\hline 1 & 0.35 & 2617 & 2010 & A11-C04A & $\begin{array}{l}\text { Surface } \\
\text { treatment } \\
\text { painting, } \\
\text { printing }\end{array}$ \\
\hline 2 & 0.33 & 2336 & 2012 & S06-G10 & $\begin{array}{l}\text { Applications of } \\
\text { ink-jet printing } \\
\text { technology }\end{array}$ \\
\hline 3 & 0.24 & 1714 & 2010 & S06-K99C & Printer \\
\hline 4 & 0.18 & 4741 & 2014 & $\mathrm{X} 25-\mathrm{A} 08 \mathrm{M} 2$ & Plastics \\
\hline 5 & 0.18 & 558 & 2010 & T01-J10C4 & 3-dimensional \\
\hline
\end{tabular}

The node centrality value measures whether the node is at the center of the co-citation network of the knowledge graph drawn by CiteSpace software. If the node's centrality is high, it means that the node has a closer relationship with other nodes[5], which is reflected in the knowledge graph. The more nodes are at the center of the co-citation network. Table 3 lists the first five manual codes identified by the 3D printing technology sorted by centrality. The centrality value of the first node is 0.35 , which is slightly higher than the centrality of the 
remaining 4 nodes. The meaning of manual code is Surface treatment-painting, printing. The second is the manual code node with a centrality of 0.33 , which represents Applications of ink-jet printing technology. As can be seen from the centrality of the nodes, the technical hotspots of the patents related to 3D printing technology mainly focus on 3D data computer modeling, threedimensional model modeling and the 3D printing technology (rapid prototyping technology and printing output technology) completed by applying these technologies. It is basically consistent with the conclusion drawn according to the cited frequency.

The Derwent manual code covariance plot as shown in Figure 2 was converted to the corresponding Timezone plot as

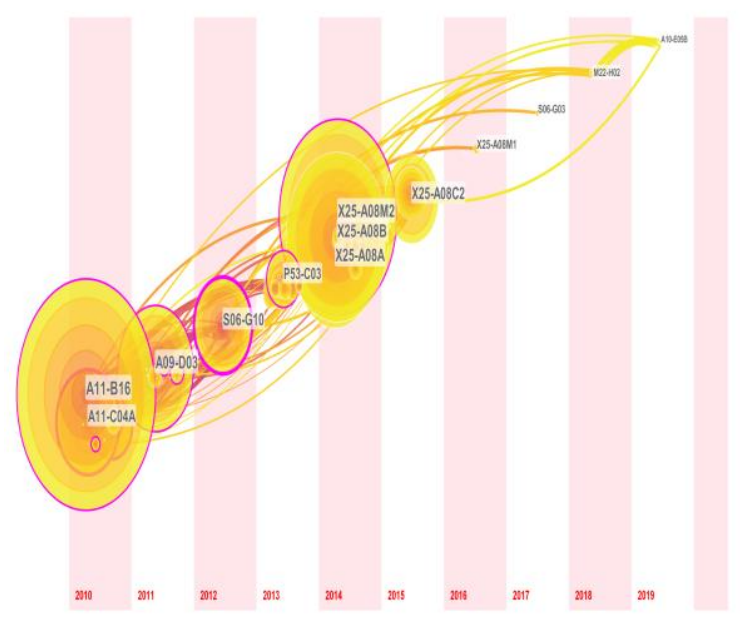

Figure 3. 3D printing technology forefront of the development of time zone map Spectrum

shown in Figure 3. By tagging nodes with a certain emergence rate in each year, we can get an evolutionary map of the frontiers of development in the wearable device space. In order to further understand the evolution of the hot research areas and research frontiers of 3D printing technology in the decade 2010-2019, the nodes with red circles in each year are included in Table 4 as representatives of the technology frontiers in that year, and if there are no nodes with red circles in a given year, the nodes that are marked most frequently in that year can be included as representatives of their technology frontiers, forming an evolutionary path of the hot research areas of 3D printing technology frontiers.

Figure 3. 3D printing technology forefront of the development of time zone map Spectrum

It can be seen from Table 4 that during the past 10 years, the research frontier of 3D printing technology has gone through such a path: "Stereographic moulding " -> " Equipment control, safety devices other " -> " Applications of ink-jet printing technology " to " Compacting and/or sintering " to " Fused deposition modeling " $>$ " Printhead details " $>$ " Powder metallurgy - powder treatment prior to use " $>$ " Chemical modification by carbonisation " $>$ " Stereographic moulding " -> " Equipment control, safety devices others ".
In the $3 \mathrm{D}$ printing technology intraoperative evolution, patents focus first on conventional printing techniques in this field, i.e. how, what kind of approach for the use of $3 \mathrm{D}$ printing. Then began relates to $3 \mathrm{D}$ printing material, $3 \mathrm{D}$ printing control-related patents, and the use of $3 \mathrm{D}$ printing technology in traditional industrial patent other than the manufacture of a new field, for example the biomedical field, bone tissue engineering. Due to the rise of the 3D printing boom in recent years, its potential advantages in other application areas have been continuously released, and the hotspots of technology research and development have once again returned to how to innovate $3 \mathrm{D}$ printing methods and related materials.

From the analysis of patent knowledge map, we can see that 3D printing technology is not only applied to an isolated technical field, but also widely used in many fields, such as metallurgy and mining, materials science and other fields; at the same time new materials and new modeling The emergence of technology has also provided effective support for the development of 3D printing, which gives related industries unique advantages in product design and manufacturers of complex special products.

TABLE 4. 3D printing technology frontier evolution path

\begin{tabular}{|c|c|c|c|}
\hline years & $\begin{array}{c}\text { Derwent } \\
\text { manual } \\
\text { code }\end{array}$ & Busrt value & Technological frontier \\
\hline 2010 & A11-B16 & & Stereographic moulding \\
\hline 2011 & A09-D03 & & $\begin{array}{l}\text { Equipment control, safety } \\
\text { devices others [exc. for } \\
\text { moulding processes, } \\
\text { involving extruders }\end{array}$ \\
\hline 2012 & S06-G10 & 105.2469 & $\begin{array}{l}\text { Applications of ink-jet } \\
\text { printing technology }\end{array}$ \\
\hline 2013 & P53-C03 & & Compacting and/or sintering \\
\hline 2014 & $\begin{array}{l}\text { X25- } \\
\text { A08M2 }\end{array}$ & & Plastics \\
\hline 2015 & $\begin{array}{l}\mathrm{X} 25- \\
\mathrm{A} 08 \mathrm{C} 2\end{array}$ & & Fused deposition modeling \\
\hline 2016 & $\begin{array}{l}\mathrm{X} 25- \\
\mathrm{A} 08 \mathrm{M} 1\end{array}$ & & Metals \\
\hline 2017 & S06-G03 & & Printhead details \\
\hline 2018 & M22-H02 & & $\begin{array}{l}\text { Powder metallurgy - powder } \\
\text { treatment prior to use }\end{array}$ \\
\hline 2019 & A10-E05B & & $\begin{array}{l}\text { Chemical modification by } \\
\text { carbonisation }\end{array}$ \\
\hline 2010 & A11-B16 & & Stereographic moulding \\
\hline 2011 & A09-D03 & & $\begin{array}{l}\text { Equipment control, safety } \\
\text { devices others [exc. for } \\
\text { moulding processes, } \\
\text { involving extruders] }\end{array}$ \\
\hline
\end{tabular}

From the technological frontier evolution path table, there are several years of frontier areas of 3D printing technology concentrated in the field of printed materials. This reflects the need for practical applications for new $3 \mathrm{D}$ printing consumables, and the forming properties of the materials will continue to improve to meet the needs of different industries. In addition, for the automation industry, with the continuous development of 3D printing technology, 3D printers will have higher requirements for control algorithms. Several years of technology frontiers in the field of control have also validated this view. "In order to improve the quality of model forming while reducing the molding time, existing control algorithms will be gradually improved or replaced" [8] 


\section{THE EVOLUTION OF 3D PRINTING TECHNOLOGY HAS BROUGHT ABOUT CHANGES IN THE CULTURAL AND CREATIVE INDUSTRIES}

With the rise of $3 \mathrm{D}$ printing, the manufacturing pattern has changed from the previous centralized and large-scale specialized manufacturing to the decentralized, smallvolume social manufacturing[9]. Although 3D printing technology has been in existence for more than a decade, the 3D printing industry is still in the early stage of development, and its business is not yet abundant. The radiation-driven effect of the cultural and creative industry is limited. With 3D printing technology matures, independent designers will become less and less dependent on traditional processing industries, except have a certain exterior design, research, and development capabilities of the professional designers, every consumer may become a designer and producers, 3D printing will be further changes in art and design and now industrial design line pattern industry.

From the knowledge graph analysis of technological evolution, it can be seen that from the perspective of the main industrial chain of 3D printing technology, in the future, technical breakthroughs will be generated from the two main lines of "modeling technology" and "printing materials". The difficulties in the upstream of the 3D printing industry chain are mainly at the level of modeling technology. A breakthrough in modeling technology will reduce the operating costs of the entire industry and expand the broader market. For the material industry, through the current competition between printing material providers and the market rules, the market standard for 3D printing materials will eventually be formed, which will also help 3D printing build a mature industrial chain.

The crowdsourcing model of cultural and creative enterprises will become an important carrier for 3D printing technology to realize commercial value. With the social manufacturing brought about by $3 \mathrm{D}$ printing technology, the new social design pattern - "design crowdsourcing" will also be popular [10]. mode crowdsourcing is respected in many fields and applications, and promote the service to become one kind of new force outsourcing service innovation. The construction and modification of the online collaborative production 3D model in the form of crowdsourcing has become routine. The current large-scale collaborative production emphasizes the absorption of consumer will or innovative ideas into the production process, thereby promoting the innovation of production and the launch of products that meet the diverse needs of consumers.

The wide application of 3D printing technology makes the two aspects of product design and manufacturing independent, so designers need to continuously strengthen and improve their understanding, use, and development of design theory content. First, designers will spread directly to consumers, taught design theory corresponding content; secondly, designed as a trading commodity, which is rich in personal behavior designer, design-build, market performance and other comprehensive information [11] The interaction between designers and users is stronger, design satisfaction can get real feedback, change the process of value creation, more personalized and niche.

\section{ANALYSIS OF THE PROMOTION STRATEGY OF 3D PRINTING TECHNOLOGY IN THE FIELD OF CULTURAL AND CREATIVE INDUSTRIES}

From the analysis of knowledge maps, it can be seen that there are no technical hot spots in some key technologies and links in the cultural and creative industry segmentation industry. Model scanning and motion capture tools for 3D printing technology require a series of technical conditions such as model acquisition equipment and application software, including simulation technology, computer graphics technology, data transmission technology, etc. However, related technologies do not appear in hot research fields. Medium. Without the support of these technology platforms, the development of $3 \mathrm{D}$ printing technology will be limited by the source of the printed prototype material. Therefore, industrial planning should give priority to the development of 3D scanning and modeling technology research and development platform with independent intellectual property rights, which will help to improve product development level in industrial design and art design and expand the application space of $3 \mathrm{D}$ printing.

the long-term development of cultural and creative industries is able to obtain a high-tech international competition seat place, depend not only on the technical aspects of competitive advantage, more importantly, but that is also whether to provide appropriate technology development policies and Business Environment. The industrial development guidance policy needs to pay attention to the top-level design of 3D printing technology and cultural and creative industry development, and it is necessary to formulate a 3D printing industry development plan and promote its priority development [12]. From it is clear that knowledge map analysis, print materials has become a $3 \mathrm{D}$ printing hot topics in the field of, The core research and development links in the fields of materials that determine the performance of printed products require policy industry optimization to form a good industrial ecology and avoid future formation Shortcomings in the industrial chain.

Relevant planning in the art design and industrial design industries needs to pay attention to the differentiation of the business brought about by technological evolution. The domestic commercialization process in the field of 3D printing is relatively slow and lagging behind, and a relatively complete industrial chain has not yet been formed. The differentiation of the format will result in a new division of labor. 3D printing industry development will be on the correlation with shared resources and services industry demand, once formed a complete industrial chain is able to lead the entire industry cluster.

$3 \mathrm{D}$ printing related management regulations and policies, the Ministry of Industry Information Technology, the Ministry of Commerce and other departments need to establish a sound legal and regulatory system and supervise the implementation. 3D printing technology has been widely used in industrial design, medical, personalized design and other fields, and development prospects, and then while $3 \mathrm{D}$ printing itself contains certain inherent risks - intellectual property, hazardous materials, and human ethics and other aspects of the 
problem. [13] these regulatory issues accompanying the evolution of technology cannot be reasonably resolved and become a key constraint and bottleneck in the development of 3D printing in the future, policymakers and industry authorities need to develop forward-looking management measures to deal with them.

\section{SUMMARY}

This paper analyzes the patent data measurement of 3D printing technology since 1962-2020 and the research hotspots analysis of 3D printing technology in recent years. It can be seen that the $3 \mathrm{D}$ printing related patents mainly focus on modeling molding technology and additional materials. technology. From the analysis of patent knowledge map, we also can see that $3 \mathrm{D}$ printing technology is not only applied to an isolated technical field, but also widely used in many fields, such as metallurgy and mining, materials science and other fields; at the same time new materials and new modeling The emergence of technology has also provided effective support for the development of 3D printing, which gives related industries unique advantages in product design and manufacturers of complex special products. Then it analyzes the changes brought about by the development of $3 \mathrm{D}$ printing technology to the cultural and creative industry. From the above analysis, it can be seen that although the impact of $3 \mathrm{D}$ printing technology on the cultural and creative industry is still in early stage, it has promoted The transformation of the centralized largescale specialized manufacturing into decentralized and small-batch social manufacturing, which also has made product design and manufacturing independent. These effects are a huge driving force for the transformation of the cultural and creative industry. Finally, this paper proposes targeted the relevant policy recommendations for the development of cultural and creative industries.

\section{REFERENCES}

1. Chen C. Searching for intellectual turning points: Progressive knowledge domain visualization. PNAS 101 2004, (1): 5303 5310.

2. Chen C. CiteSpace: Detecting and visualizing emerging trends and transient patterns in scientific literature. Journal of the American Society for Information Science and Technology 2006, 57(3): 359-377.

3. Chen $\mathrm{C}, \mathrm{Hu} \mathrm{Z}$, Liu $\mathrm{S}$, et al. Emerging trends in regenerative medicine: a scientometric analysis in CiteSpace. Expert Opinion on Biological Therapy 2012, 12(5):593- 608.

4. Chen C, Hu Zhigan, Liu Shengbo, Tseng Hung. Emerging trends in regenerative medicine: A scientometric analysis in CiteSpace [J]. Expert Opinionon Biological Therapy, 2012, 12(5): 593-608.

5. Chen C. Science Mapping: A Systematic Review of the Literature[J]. Journal of Data and Information Science, 2017, 2(2): $1-40$

6. Hou Jianhua, Hu Zhigang. CiteSpace. Retrospect and Prospect of application software research. Modern intelligence 2013, 33 (4): 99-103.

7. Li Chunyan. Technology life cycle judgment method based on patent information analysis [J]. Modern Information 2012, (2): 98-101.

8. Li Suangsuang, Wang Feiyue. 3D printing technology art and social manufacturing. Oriental Morning Post 2013
9. Yan Honglei. Application of 3D Printing in Cultural Creative Product Design. Modern Manufacturing Technology and Equipment, 2019, (8): 112-113.

10. Zhang Nan, Li Fei. The Influence of the Development and Application of 3D Printing Technology on Future Product Design [J]. Mechanical Design 2013, 30(007): 97-99.

11. ong Jiawei, Yang Lei. Product Green Design Based on 3D Printing Technology. Journal of Lanzhou Jiaotong University 2013, 32(5): 116-119.

12. Hong Wangzhong, Li sail, Zhang Man Yin. China 3D status quo of the printing industry and development Exhibition think the road. By the economic aspect 2013, 1: 90-93.

13. Qing Liubu. 3D play printing technology inherent risk of legal norms and policies. Science. Economic. Social 2013, 31 (2): $130-132$ 